\title{
Considering behavioral interventions for comorbid psychiatric problems in Prader-Willi Syndrome: response to Bonnot et al.
}

\author{
Eric A. Storch ${ }^{1}$
}

Received: 29 November 2015 / Accepted: 4 December 2015 /Published online: 21 December 2015

(C) Springer-Verlag Berlin Heidelberg 2015

To the editor:

I read with great interest Bonnot et al.'s review of psychopharmacotherapy for Prader-Willi Syndrome (PWS). Given the frequency with which comorbid psychiatric conditions are present in patients with PWS, establishing evidencebased therapies is of critical importance.

Within the strengths of this article (e.g., clinical relevance), there was limited discussion of behavioral psychotherapeutic interventions for comorbid psychiatric conditions in PWS. This is of particular concern given the limited information that can be concluded based on the strength of the available literature, which consists of case reports and small open trials. The side effect profile of many medications, especially antipsychotics (i.e., weight gain, increased appetite), makes their use a last resort in this population, and some parents may find pharmacotherapy an undesirable treatment approach. Tailored behavioral interventions have demonstrated sound efficacy among youth with developmental disabilities in treating anxiety/ obsessive-compulsive symptoms [1], disruptive behavior [2], and self-injury [3] with a negligible side effect profile; preliminary effectiveness among youth with PWS presenting with obsessive-compulsive and skin picking symptoms has been demonstrated [4]. Thus, clinicians should base treatment decisions on a complete assessment of all available therapies; when data are limited in PWS, extrapolation from the treatment literature in disorders with similar phenomenology may be appropriate to most effectively and safely treat the affected individual.

\section{Communicated by Jaan Toelen}

Eric A. Storch

estorch@health.usf.edu

1 USF Health Morsani College of Medicine, St. Petersburg, FL, USA
In sum, the reader should use caution in applying findings from this report into their clinical practice given the strength of the current literature supporting pharmacotherapy. Behavioral interventions may be an important treatment component for this population, and the psychiatric care of patients with PWS should be multidisciplinary involving physicians, psychologists, and other allied health professionals. Collectively, the limited available data on pharmacological and behavioral interventions highlight the need for further clinical trials investigating potentially viable therapies that incorporate outcome instruments designed for and validated in people with PWS.

Eric A. Storch, Ph.D.

Professor and All Children's Hospital Guild Endowed Chair University of South Florida

Clinical Director, Rogers Behavioral Health—Tampa Bay

\section{References}

1. Ung D, Selles R, Small BJ, Storch EA (2015) A systematic review and meta-analysis of cognitive-behavioral therapy for anxiety in youth with high-functioning autism spectrum disorders. Child Psychiatry Hum Dev 46:533-547

2. Brookman-Frazee L, Stahmer A, Baker-Ericzen MJ, Tsai K (2006) Parenting interventions for children with autism spectrum and disruptive behavior disorders: opportunities for cross-fertilization. Clin Child Fam Psychol Rev 9:181-200

3. Peters-Scheffer N, Didden R, Korzilius H, Sturmey P (2011) A metaanalytic study on the effectiveness of comprehensive ABA-based early intervention programs for children with Autism Spectrum Disorders. Res Autism Spect Dis 5:60-69

4. Storch EA, Rahman O, Morgan J, Brauer L, Miller J, Murphy T (2011) Case series of behavioral psychotherapy for obsessivecompulsive symptoms in youth with Prader-Willi Syndrome. J Dev Phys Disabil 23:359-368 